\title{
Predicting Effects of Demographic, Linguistic and Psychological Variables on University International Students' Intercultural Communication Sensitivity
}

\author{
Meihua Liu ${ }^{1}$ \\ Department of Foreign Languages and Literatures, Tsinghua University, China
}

\begin{abstract}
With globalization, intercultural communication plays an increasingly more important role in various fields, including business, transportation and education. It is the same with intercultural sensitivity (IS), a critical component of intercultural communication. Though much research has been done on IS, little can be found on effects of demographic, linguistic and psychological factors on learners' IS simultaneously in the same context. Little research can be found on IS in learners of languages other than English either. For these reasons, the present study investigated the predicting effects of linguistic, psychological and demographic variables on university international students' intercultural communication sensitivity when immersed in the Chinese culture. One hundred and sixty-seven international students studying in a Chinese university in Beijing answered the Intercultural Sensitivity Scale, the Willingness-to-Communicate in Chinese Scale as well as the Demographic Questionnaire, and self-rated their proficiency in Chinese. Analyses of the data revealed the following main findings: (1) the participants were generally (fairly) sensitive, confident, attentive and enjoyable in intercultural interactions and respected cultural differences when communicating with people from the Chinese culture, (2) interaction engagement, interaction confidence, and overall intercultural communication sensitivity were significantly positively related to the participants' ability to effectively communicate with people from the Chinese culture; interaction engagement was also significantly correlated with the participants' openness to the Chinese culture, and (3) ability to effectively communicate with people from the Chinese culture and use of Chinese were powerful positive predictors for intercultural communication sensitivity. These findings imply that intercultural communication sensitivity is closely related to learners' linguistic, psychological and demographic variables. Based on these findings, some implications were discussed.

Keywords: demographic variable, effect, intercultural communication sensitivity, linguistic variable, psychological variable.
\end{abstract}

\section{Introduction}

Intercultural communication has become increasingly important with globalization, the effectiveness of which depends on various linguistic, cultural, educational and demographic variables, such as proficiency in and contact with the target language, age, gender, education level, anxiety, and willingness to communicate in the target language (Hannigan, 1990; Jimenez, 2003; Liu, 2017; Shively, 2008). Nevertheless, little research on the effects of these variables on intercultural communication has been done, especially simultaneously in the same context, as reviewed below. It is the same with intercultural communication sensitivity, an important component of intercultural communication (Chen \& Starosta, 2000; Tamam, 2010; Yurtseven \& Altun, 2015). Moreover, review of the current literature shows that most research on intercultural communication or intercultural communication sensitivity focuses on individuals learning English as a second/foreign language (SL/FL). Research on intercultural communication or intercultural communication sensitivity in learners of SLs/FLs other than English is rather scarce yet worthwhile. For these reasons, the present study intended to investigate the predicting effects of linguistic, psychological and demographic variables on university international students' intercultural communication sensitivity when immersed in the Chinese culture.

\footnotetext{
${ }^{1}$ Correspondent email: liumeihua@mail.tsinghua.edu.cn
} 


\section{Literature Review}

Intercultural communication sensitivity (ICS), a critical component of intercultural communication competence (Chen \& Starosta, 1996, 2000; Tamam, 2010), refers to interactants' ability to transform themselves affectively, cognitively and behaviorally in the developmental process of intercultural communication (Bennett, 1986). According to Chen and Starosta (2000, p.231), ICS is an "active desire to motivate [oneself] to understand, appreciate, and accept differences among cultures". Covering six stages-denial, defense, minimization, acceptance, adaptation and integration, ICS affects how successful intercultural encounters are and predicts intercultural communication competence (Chen \& Starosta, 1997, 2000). To measure ICS, several scales have been developed like the Developmental Model of Intercultural Sensitivity (Bennett, 1986), the Intercultural Development Inventory (Hammer \& Bennett, 1998) and the Intercultural Sensitivity Scale (Chen \& Starosta, 2000). Of these measures, the Intercultural Sensitivity Scale (ISS) has been widely applied in empirical studies and proved to be highly reliable and valid (Alaei \& Nosrati, 2018; Altshuler, Sussman, \& Kachur, 2003; Çiloğlan \& Bardakçı, 2019; Dong, Day \& Collaço, 2008; Kim, 2004; Nieto \& Booth, 2009; Olson \& Koeger, 2001; Penbek, Şahin \& Cerits, 2012; Ersoy \& Uysal, 2018; Pritchard \& Skinner, 2002; Straffon, 2003; Yu \& Chen, 2008; Yurtseven \& Altun, 2015). It intends to help individuals "distinguish how their culturally different counterparts vary in behaviors, perceptions, and feelings so that they may be conscious and respectful within their interaction" (Chen \& Starosta, 2000, p.4). As discussed in Chen and Starosta (2000), the ISS, a 5-point Likert scale, includes 24 items with 5 factors: interaction engagement, respect for cultural differences, interaction confidence, interaction enjoyment, and interaction attentiveness.

Studies using the ISS (e.g., Çiloğlan \& Bardakçı, 2019; Dong et al., 2008; Liu, 2017, 2018b; Matsumoto \& Hwang, 2013; Nieto \& Booth, 2009; Olson \& Koeger, 2001; Penbek et al., 2012; Pritchard \& Skinner, 2002; Rahimi \& Soltani, 2011; Straffon, 2003; Yu \& Chen, 2008; Yurtseven \& Altun, 2015), as well as those using other self-reports (e.g., Anderson, Lawton, Rexeisen \& Hubbard, 2006, Byram, 1997; Christmas \& Barker, 2014; Engle \& Engle, 2004; Hammer \& Bennett, 1998; Jackson, 2011; Liu \& Liu, 2015; Lukesová, 2015; Martinsen, 2011; Straffon, 2003; Tabatadze \& Gorgadze, 2014; Tamam \& Krauss, 2014), reveal that interactants' respect for different cultures improves with the level of engagement in international interactions, and that intercultural communication sensitivity and multiculturalism greatly help to reduce individuals' ethnocentrism. These studies also discover that interactants' intercultural sensitivity levels are positively correlated with their individual characteristics like gender, education levels, study abroad experiences, contact with and proficiency in the target language, multicultural awareness and multicultural education. For example, Chen and Starosta (2000) administered the ISS and other questionnaires to 162 university students. The study showed that interculturally sensitive students were more attentive, more emphatic and more sensitive while having intercultural encounters and were more positive towards and more effective in intercultural interaction. Straffon's (2003) study of 336 international high school students and Peng's (2005) study of 833 people from China and Thailand further confirmed that ICS was positively related to the participants' exposure to the target language and culture. In Engle and Engle's (2004) study, the participants who were in a year-long study abroad program answered the Intercultural Development Inventory three times. The results showed that the participants made significantly more progress than others in areas of cultural understanding and cross-cultural communication and that their rate of progress increased significantly in the second term. Though the sample size was small ( 25 students by the end of the study), this finding further confirmed the positive correlation between intercultural sensitivity and contact with/use of a SL/FL (Bae \& Song, 2017; Kratt, 2018; Olson \& Koeger, 2001; Peng, 2005; Straffon, 2003). To assess the relationship between intercultural sensitivity and intercultural communication competence among international postgraduate students at a Malaysian university, Sarwari and Wahab (2017) collected quantitative and interview data from 108 international postgraduate students from 17 different countries. The results demonstrated that intercultural sensitivity and intercultural communication competence were two main factors that helped individuals to conduct proper and effective intercultural communication with people from different cultures and that they mutually affected each other (Kotluk \& Kocakaya, 2018). These findings were partially supported in Alaei and Nosrati (2018) which explored Iranian EFL teachers' levels of intercultural communication competence and intercultural sensitivity.

In order to explore the effects of cultural, affective, and linguistic variables on adult CSL learners' willingness to communicate in Chinese (WTCC), Liu (2017) administered the ISS as well as other questionnaires to 162 adult international students in China. The study uncovered that Chinese speaking anxiety, length of stay in China, Chinese learning motivation, intercultural communication sensitivity and Chinese proficiency powerfully predicted the participants' WTCC. To explore the relationship between intercultural sensitivity and language achievement of EFL (English as a foreign language) learners in Turkey, Çiloğlan and Bardakçı (2019) administered the Intercultural Sensitivity Scale to Turkish university students and collected 325 valid questionnaires. The findings showed a statistically significant positive correlation between intercultural sensitivity and students' English language achievement. The study also showed that the more proficient students scored significantly higher on the Intercultural Sensitivity Scale than their less proficient peers, although no significant difference occurred in intercultural sensitivity scores between female and male respondents. Likewise, Morales's (2017) survey study of 139 international high school students revealed no significant difference in intercultural 
sensitivity between male and female students but significant difference between Korean and non-Korean students. Yilmaz (2019) examined the difference in university students' intercultural sensitivity in terms of age, gender, native language, English proficiency, years of learning English and experiences abroad. Two hundred and thirtytwo Turkish public and private university students participated in the study and answered questionnaires on intercultural sensitivity and intercultural communication competence. This study, nevertheless, revealed significant difference in intercultural sensitivity in terms of gender and English proficiency but no significant difference in relation to other variables.

As reviewed, intercultural communication sensitivity is closely related to various linguistic, psychological, educational and demographic variables such as proficiency in and contact with the target language and culture, willingness to communicate in a SL/FL, gender, and language learning motivation. Nevertheless, some studies have revealed different findings (Bae \& Song, 2017; Çiloğlan \& Bardakç1, 2019; Liu, 2018b; Morales, 2017; Tamam \& Krauss, 2014; Yilmaz, 2019; Yurtseven \& Altun, 2015). Yurtseven and Altun's (2015) analyses of 220 questionnaires collected from pre-service teachers in America indicated that there was no significant difference in the ICS levels in regard to gender, study abroad experience, and contact with the target language and culture. The study also implied that inadequate multicultural awareness and little or no multicultural education negatively affected intercultural sensitivity levels. Their finding was partially supported by Liu (2018b) who administered the ISS and other questionnaires to 74 CSL (Chinese as a second language) learners studying in a university in Beijing. The findings indicated that the participants' intercultural sensitivity was not statistically significant correlated with their background variables like gender, use of Chinese, proficiency in Chinese and length of stay in China. This is probably because the concepts and interpretations of intercultural communication competence are changing and vary in different contexts, so are those of intercultural communication sensitivity, as discussed in Collier (2015), which requires a clear working definition of intercultural communication competence in a specific study.

Concurrently, these mixed findings mean that more research is needed to reveal a fuller picture of intercultural communication sensitivity in various contexts. Moreover, to date, few studies have ever examined the relationship between intercultural communication sensitivity and diverse linguistic, psychological, educational and demographic variables in the same context. Consequently, the present study, targeting international students studying in a university in Beijing, aimed to investigate the predicting effects of linguistic, psychological and demographic variables on their intercultural communication sensitivity when immersed in the Chinese culture. In this context, intercultural communication sensitivity referred to their active desire/motivation to understand, appreciate, and accept differences between the Chinese culture and their own native cultures.

\section{Research Method}

Participants. One hundred and sixty-seven (66 male and 101 female) international students studying in a prestigious university in Beijing participated in the present study. With an age range of 17-39 and an average age of 22.23 ( $\mathrm{SD}=3.96$ ), most participants were single (159) and registered in various disciplines, who came from various countries and regions and spoke different native languages such as Korean, English, German, French, Spanish, Turkish, Russian and Dutch. They all reported to have some or (very) good knowledge of English. As they reported, they had stayed in China for an average of 5.36 years $(\mathrm{SD}=4.76)$ and spent an average of 5.83 years ( $\mathrm{SD}=5.01)$ studying Chinese. Of these participants, 60 (35.9\%) passed HSK (Chinese proficiency test) level 6, $38(22.8 \%)$ passed HSK level 3, 22(13.2\%) passed HSK 5, with others passing other HSK levels (see Table 1).

Table 1.

\begin{tabular}{|c|c|c|c|c|c|c|c|c|c|c|}
\hline \multicolumn{2}{|c|}{$\begin{array}{l}\text { Total } \\
\text { number }\end{array}$} & \multicolumn{2}{|l|}{ Age } & \multicolumn{2}{|c|}{ Marital status } & \multicolumn{2}{|c|}{ LSC (year) } & \multicolumn{2}{|c|}{ TSLC (year) } & \multirow[t]{2}{*}{ HSK level } \\
\hline $\mathrm{M}$ & $\mathrm{F}$ & $\mathrm{M}$ & $\mathrm{SD}$ & $\begin{array}{l}\text { Marrie } \\
\text { d }\end{array}$ & Unmarried & $\mathrm{M}$ & SD & $\mathrm{M}$ & $\mathrm{SD}$ & \\
\hline 66 & 101 & $\begin{array}{l}22.2 \\
3\end{array}$ & 3.96 & 8 & 159 & 5.36 & 4.76 & 5.83 & 5.10 & $\begin{array}{l}0: 6 / 3.6 \% \\
1: 17 / 10.2 \% \\
2: 16 / 9.6 \% \\
3: 38 / 22.8 \% \\
4: 8 / 4.8 \% \\
5: 22 / 13.2 \% \\
6: 60 / 35.9 \%\end{array}$ \\
\hline
\end{tabular}

Notes. $\mathrm{M}=$ male; $\mathrm{F}=$ female; $\mathrm{M}=$ mean; $\mathrm{SD}=$ standard deviation

$\mathrm{LSC}=$ length of stay in China; TSLC $=$ time spent in learning Chinese; HSK $=$ Chinese proficiency test.

Instruments. The respondents in the present study answered a battery of questionnaires intending to elicit 
their demographic, linguistic and psychological information as well as intercultural communication sensitivity.

Intercultural Sensitivity Scale (ISS). To measure the participants' intercultural communication sensitivity level, the 24-item Intercultural Sensitivity Scale (ISS) designed by Chen and Starosta (2000) was adapted in the present study. To better fit the present situation, phrases like 'different cultures' and 'other culture' in the original ISS were changed to be 'the Chinese culture'. Thus, the resultant ISS primarily meant to measure the participants' sensitivity levels to the Chinese culture in interactions with the Chinese. Designed on a 5-point Likert scale ranging from 'strongly disagree' to 'strongly agree' with values 1-5 assigned to each alternative, the ISS covers five dimensions, as discussed in Chen and Starosta (2000): 7-item Interaction Engagement (IENG), 6-item Respect for Cultural Differences (RCD), 5-item Interaction Confidence (IC), 3-item Interaction Enjoyment (IENJ), and 3item Interaction Attentiveness (IA). As illustrated in Chen and Starosta (2000), the IENG items are indicative of participants' feeling of participation in intercultural communication, the RCD items imply how participants orient to or tolerate their counterparts' culture and opinion, the IC items are suggestive of participants' confidence in intercultural settings, the IENJ items are related to participants' positive or negative reaction towards communicating with people from diverse cultures, and the IA items are concerned with participants' effort to understand what happens in intercultural interaction.

In addition, the respondents were asked to self-rate their openness to the Chinese culture (OCC) and ability to effectively communicate with people from the Chinese culture (AECPCC) on a scale of 1 (rather bad) to 5 (excellent), respectively. It is generally acknowledged that open-minded people are willing to tolerate, understand and appreciate cultural differences in intercultural communication (Bennett, 1986; Chen \& Starosta, 2000).

Willingness-To-Communicate in Chinese Scale (WTCCS). To measure respondents' willingness to communicate, an important psychological variable, the 20-item Willingness-To-Communicate Scale (WTCS) developed by McCroskey (1992) was adapted in the present research. This WTCS asks respondents to indicate the percentage (0-100) of time they would choose to communicate in a SL/FL in 20 situations (e.g., "Talk with a stranger" and "Talk with an acquaintance"). To suit the present situation, the phrase "in Chinese" was added to each item, which resulted in the Willingness-To-Communicate in Chinese Scale (WTCCS) used thereafter in the study. Similar to the original WTC Scale described in McCrosky (1992), this WTCCS measured participants' predisposition toward approaching or avoiding the initiation of communication in Chinese with various types of audiences in different communication contexts. The higher the score, the more willing a respondent was to communicate in Chinese. Meanwhile, the respondents were required to self-rate their overall willingness to communicate in Chinese (OWTCC) on a scale of 1 (rather bad) to 5 (excellent).

The Demographic Questionnaire. The Demographic Questionnaire consisted of eight items, intending to collect such demographic information about the participants as age, gender, marital status, native language, length of stay in China, time spent in learning Chinese, use of Chinese every day, and HSK (Chinese proficiency test) level.

Proficiency in Chinese. To measure the participants' proficiency in Chinese, they were required to selfrate their overall proficiency in Chinese as well as proficiency in speaking and listening Chinese since they are closely related to intercultural communication on a scale of 1 (rather poor) to 5 (excellent), respectively. Meanwhile, the levels of Chinese Proficiency Test (HSK) for speakers of other languages they recently passed were collected. HSK, ranging from level 1 (lowest) to level 6 (highest), is a standardized written test for learners of Chinese as a SL/FL for education and employment in China.

Procedure and data analyses. The questionnaires in both Chinese and English, together with a consent form, were administered to international students in class by their course teachers during the last two weeks of a 16-week semester, which were answered in 15 minutes. All the data were analyzed using SPSS 20. Means, standard deviations and reliability scores were computed to reveal the general patterns of the measured variables. Correlation analyses were run to explore the associations between intercultural communication sensitivity and other measured variables. Then multiple (stepwise) regression analyses were conducted to identify the predictors for intercultural communication sensitivity.

\section{Results}

The components and scoring scheme of the ISS described in Chen and Starosta (2000) and confirmed in Fritz, Möllenberg \& Chen (2002) were adopted in the present study. When computing the scores, items reflective of low/poor intercultural communication sensitivity had their values reversed, as specified in Chen and Starosta (2000). Thus, the higher the score, the more sensitive a respondent was in intercultural communication.

\section{Means, standard deviations and reliability scores of ISS scales and other measures}

Table 2 presents the means, standard deviations and reliability scores of the ISS scales and other measures employed in the study. As shown in Table 2, the overall ISS (Intercultural Sensitivity Scale) and WTCCS (Willingness-to-Communicate in Chinese Scale) were highly reliable in this research, with a reliability score of .905 and .944 respectively, so were the ISS subscales (Cronbach coefficient $a=.538 \sim .818$ ) though their reliability scores were not so high as the ISS'. 
Table 2.

Means, Standard Deviations and Reliability Scores for ISS Scales and other Measures (N = 167)

\begin{tabular}{|c|c|c|c|c|c|c|}
\hline & Mean & $S D$ & Skewness & Kurtosis & $\begin{array}{l}\text { Number } \\
\text { of items }\end{array}$ & Reliability \\
\hline $\begin{array}{l}\text { Interaction engagement } \\
\text { (IENG) }\end{array}$ & 3.64 & .67 & -.165 & -.091 & 7 & .595 \\
\hline $\begin{array}{l}\text { Respect for cultural } \\
\text { differences }(\mathrm{RCD})\end{array}$ & 3.85 & .84 & -.859 & .546 & 6 & .764 \\
\hline $\begin{array}{l}\text { Interaction confidence } \\
\text { (IC) }\end{array}$ & 3.40 & .80 & .264 & -.352 & 5 & .725 \\
\hline $\begin{array}{l}\text { Interaction enjoyment } \\
(\text { IENJ) }\end{array}$ & 3.70 & 1.06 & -.608 & -.400 & 3 & .818 \\
\hline $\begin{array}{l}\text { Interaction attentiveness } \\
\text { (IA) }\end{array}$ & 3.42 & .81 & -.338 & .404 & 3 & .538 \\
\hline ISS & 3.63 & .66 & -.194 & -.493 & 24 & .905 \\
\hline $\mathrm{OCC}$ & 3.89 & 1.02 & -.905 & .573 & & \\
\hline AECCC & 3.53 & .99 & -.094 & -.559 & & \\
\hline WTCCS & 60.14 & 31.34 & .570 & 2.995 & 20 & .944 \\
\hline OWTCC & 3.84 & .99 & -.614 & .009 & & \\
\hline Use of Chinese (UOC) & 12.04 & 11.05 & 2.529 & 8.625 & & \\
\hline $\begin{array}{l}\text { Proficiency in listening } \\
\text { Chinese (PLC) }\end{array}$ & 3.22 & 1.26 & -.136 & -.934 & & \\
\hline $\begin{array}{l}\text { Proficiency in speaking } \\
\text { Chinese (PSC) }\end{array}$ & 3.03 & 1.28 & .119 & -1.026 & & \\
\hline $\begin{array}{l}\text { Overall proficiency in } \\
\text { Chinese (OPC) }\end{array}$ & 3.06 & 1.17 & .111 & -.818 & & \\
\hline
\end{tabular}

Notes. WTCCS = Willingness to Communicate in Chinese Scale; ISS = Intercultural Sensitivity Scale; OCC = openness to the Chinese culture; AECPCC = ability to effectively communicate with people from the Chinese culture; OWTCC = overall willingness to communicate in Chinese.

As shown in Table 2, the participants scored 3.63 on the ISS and 3.40 to 3.85 on ISS subscales, all above the scale midpoint 3, indicating that more than half participants were (quite) sensitive in intercultural communication. Meanwhile, a mean of 3.89 on OCC suggested that the respondents self-rated their openness to the Chinese culture to be (fairly) high. A mean of 3.53 on AECPCC showed that they self-rated their ability to effectively communicate with people from the Chinese culture to be (fairly) high as well. As reported in Table 2 , the respondents scored 60.14 on the WTCCS and 3.84 on OWTCC, above the scale midpoints 50 and 3 respectively, implying that they were generally willing to communicate with diverse kinds of people in various contexts in Chinese and that their overall willingness to communicate in Chinese was (fairly) high. Table 2 also shows that the participants self-reported an average of 12.04 hours spent in using Chinese every day, in spite of the large difference in hours spent in doing so as evidenced in the value of standard deviation $(\mathrm{SD}=11.05)$. Even so, they tended to self-rate their proficiency in listening, speaking and overall Chinese to be intermediate $(\mathrm{M}=3.22,3.03$ and 3.06 respectively).

Moreover, the skewness and kurtosis scores presented in Table 2 for all the scales except for WTCCS were predominantly lower than 1, implying that the scores were generally in a normal distribution for all the scales. The only exception was that the participants might vary a lot in self-reported daily use of Chinese, as indicated by its standard deviation $(\mathrm{M}=12.04, \mathrm{SD}=11.05)$ and skewness $(2.529)$ and kurtosis $(8.625)$ scores. This might be due to their varying lengths of stay in China and time spent in learning Chinese.

\section{Correlations between the ISS and other measured scales}

To explore the associations between the students' intercultural communication sensitivity and their demographic, linguistic and psychological variables, correlation analyses were run between the ISS and other measured scales (gender, marital status and native language were excluded from correlation and regression analyses due to the large ratio). The results are reported in Table 3 (To avoid Type I error, Bonferroni correction was carried out in the analyses, with the threshold of p lowered from .05 to be at .0029 and from .01 to be. 00059). 
Table 3.

Correlations between the ISS and Other Measured Scales $(\mathrm{N}=167)$

\begin{tabular}{cccccccc}
\hline & $I E N G$ & $R C D$ & $I C$ & $I E N J$ & $I A$ & $I S S$ & $O C C$ \\
\hline OCC & $.254^{* *}$ & .093 & .216 & .233 & .022 & .212 & 1 \\
AECPCC & $.249^{*}$ & .004 & $.358^{* *}$ & .225 & .181 & $.241^{*}$ & $.482^{* *}$ \\
WTCCS & .109 & .010 & .114 & .095 & .123 & .102 & .050 \\
OWTCC & .066 & .002 & .022 & .057 & -.019 & .042 & $.309 * *$ \\
UOC & .073 & .049 & .200 & .186 & .167 & .152 & -.105 \\
PLC & .014 & .109 & .053 & .100 & -.055 & .039 & $.280^{* *}$ \\
PSC & .052 & .009 & .043 & .155 & -.050 & .057 & $.368^{* *}$ \\
OPC & .061 & .039 & .054 & .154 & -.052 & .073 & $.364^{* *}$ \\
HSK level & -.219 & -.126 & -.106 & -.189 & -.183 & -.196 & -.067 \\
Age & .002 & -.049 & -.021 & .034 & .078 & -.005 & -.013 \\
LSC & .039 & .010 & -.011 & .038 & .020 & .026 & .041 \\
TSLC & -.025 & .057 & -.056 & .093 & .016 & .017 & .093
\end{tabular}

Notes. $* *=\mathrm{p} \leq .00059 ; *=\mathrm{p} \leq .0029$

coefficient of determination: small $=r \leq 0.1$; medium $=r=0.3$; large $=r \geq 0.5$ (Cohen, 1988)

$\mathrm{LSC}=$ length of stay in China; TSLC $=$ Time spent in learning Chinese

$\mathrm{HSK}=$ Chinese proficiency test.

As reported in Table 3, of the ISS scales, IENG (interaction engagement) was significantly positively correlated with OCC (openness to the Chinese culture) $(r=.254, \mathrm{p} \leq .00059)$ and AECPCC (ability to effectively communicate with people from the Chinese culture) $(r=.249, \mathrm{p} \leq .0029)$; both IC (interaction confidence) $(r=.358$, $\mathrm{p} \leq .00059)$ and ISS $(r=.241, \mathrm{p} \leq .0029)$ were significantly positively correlated with AECPCC, with a medium effect size for the coefficients. Alternatively, the more sensitive a respondent was in interaction engagement, the more open he/she was to the Chinese culture and the abler she/he was to effectively communicate with people from the Chinese culture; the more confident a respondent was in intercultural interaction or the higher a respondent's overall intercultural communication sensitivity level, the abler he/she was to effectively communicate with people from the Chinese culture, or vice versa. Meanwhile, OCC was significantly positively correlated with AECPCC $(r=.482, \mathrm{p} \leq .00059)$, OWTCC (overall willingness to communicate in Chinese) $(r=.309, \mathrm{p} \leq .00059)$, PLC (proficiency in listening Chinese) $(r=.280, \mathrm{p} \leq .00059)$, PSC (proficiency in speaking Chinese) $(r=.368, \mathrm{p}$ $\leq .00059)$, and OPC $(r=.364, \mathrm{p} \leq .00059)$, with a medium effect size for the coefficients. Namely, the more open a respondent was to the Chinese culture, the abler he/she was to effectively communicate with people from the Chinese culture, the more willing he/she was to communicate in Chinese, the more proficient he/she was in listening, speaking and overall Chinese, or vice versa.

\section{Predictors for intercultural communication sensitivity}

To explore the predictors for intercultural communication sensitivity, multiple (stepwise) regression analyses were done, with the measured demographic, linguistic and psychological variables as independent variables and the ISS scores as the dependent variable $(\mathrm{p} \leq .05)$, respectively. The results are presented in Table 4 .

As reported in Table 4, regression analyses resulted in 1 model for IENG (interaction engagement) with the change in $\mathrm{R}^{2}$ being significant at .001: AECPCC (ability to effectively communicate with people from the Chinese culture) $\left(\beta=.297, t=3.46, \mathrm{f}^{2}=.096\right)$, with a medium effect size. Meanwhile, 2 models were yielded for the ISS and its other subscales except that no model was produced for RCD (respect for cultural differences). The 2 models for IC (interaction confidence) were: .000 for model 1 (AECPCC) and .017 for model 2 (AECPCC, UOC). Both AECPCC $(\beta=.356, t=4.29)$ and UOC (use of Chinese) $(\beta=.201, t=2.43$ ) were positive predictors for IC, with a medium effect size $\left(\mathrm{f}^{2}=.175\right.$ and .032 respectively). The 2 models for IENJ (interaction enjoyment) were: .001 for model 1 (AECPCC) and .010 for model 2 (AECPCC, UOC). Both AECPCC $(\beta=.257, t=3.03$ ) and UOC (use of Chinese) $(\beta=.222, t=2.62)$ were positive predictors for IENJ, with a medium effect size $\left(\mathrm{f}^{2}\right.$ $=.093$ and .05 respectively). The 2 models for IA (interaction attentiveness) were: .001 for model 1 (UOC) and .021 for model 2 (UOC, AECPCC). Both UOC $(\beta=.256, t=2.98)$ and AECPOC $(\beta=.200, t=2.33$ ) were positive predictors for IA, with a medium effect size $\left(\mathrm{f}^{2}=.089\right.$ and .041 respectively). The 2 models for ISS (intercultural sensitivity) were: .000 for model 1 (AECPCC) and .016 for model 2 (AECPCC, UOC). Both AECPCC ( $\beta=.290$, $t=3.40)$ and $\operatorname{UOC}(\beta=.209, t=2.44)$ were positive predictors for ISS, with a medium effect size $\left(\mathrm{f}^{2}=.116\right.$ and .044 respectively). 


\section{Table 4.}

Multiple Regression Coefficients and Significance of Predictors for ISS

\begin{tabular}{|c|c|c|c|}
\hline & & \multicolumn{2}{|l|}{$A E C P C C$} \\
\hline \multirow[t]{6}{*}{ IENG } & $\beta$ & \multicolumn{2}{|l|}{.297} \\
\hline & $t$ & \multicolumn{2}{|l|}{$3.46^{* *}$} \\
\hline & $\mathrm{p}$ & \multicolumn{2}{|l|}{.001} \\
\hline & $\mathrm{df}$ & \multicolumn{2}{|l|}{1} \\
\hline & VIF & \multicolumn{2}{|l|}{1.000} \\
\hline & Cohen's $f^{2}$ & \multicolumn{2}{|l|}{.096} \\
\hline & & $A E C P C C$ & $U O C$ \\
\hline \multirow[t]{7}{*}{$\mathrm{IC}$} & $\beta$ & .356 & .201 \\
\hline & $t$ & $4.29 * *$ & $2.43^{*}$ \\
\hline & $\mathrm{p}$ & .000 & .017 \\
\hline & df & 1 & 2 \\
\hline & VIF & 1.024 & 1.024 \\
\hline & Cohen's f ${ }^{2}$ & .175 & .042 \\
\hline & & $A E C P C C$ & $U O C$ \\
\hline \multirow[t]{7}{*}{ IENJ } & $\beta$ & .257 & .222 \\
\hline & $t$ & $3.03^{* *}$ & $2.62 * *$ \\
\hline & $\mathrm{p}$ & .003 & .01 \\
\hline & df & 1 & 2 \\
\hline & VIF & 1.024 & 1.024 \\
\hline & Cohen's f ${ }^{2}$ & .093 & .05 \\
\hline & & $U O C$ & $A E C P C C$ \\
\hline \multirow[t]{7}{*}{ IA } & $\beta$ & .256 & .200 \\
\hline & $t$ & $2.98 * *$ & $2.33^{*}$ \\
\hline & $\mathrm{p}$ & .004 & .021 \\
\hline & df & 1 & 2 \\
\hline & VIF & 1.023 & 1.023 \\
\hline & Cohen's f ${ }^{2}$ & .089 & .041 \\
\hline & & $A E C P C C$ & $U O C$ \\
\hline \multirow[t]{6}{*}{ ISS } & $\beta$ & .290 & .209 \\
\hline & $t$ & $3.40 * *$ & $2.44 *$ \\
\hline & $\mathrm{p}$ & .001 & .016 \\
\hline & $\mathrm{df}$ & 1 & 2 \\
\hline & VIF & 1.024 & 1.024 \\
\hline & Cohen's f ${ }^{2}$ & .116 & .044 \\
\hline
\end{tabular}

Notes. $\mathrm{df}=$ degree of freedom; effect size of Cohen's $\mathrm{f}^{2}$ : small $=\mathrm{f}^{2} \leq .02 ;$ medium $=\mathrm{f}^{2}=.15 ;$ large $=\mathrm{f}^{2} \geq .35$ (Cohen, 1988).

\section{Discussion}

Statistical analyses showed that the ISS and its subscales were (highly) reliable, as found in Chen and Starosta (2000) and other studies (Dong et al., 2008; Fritz et al., 2002; Liu, 2017; Matsumoto \& Hwang, 2013; Nieto \& Booth, 2009; Olson \& Koeger, 2001; Penbek et al., 2012; Yilmaz, 2019). The analyses also revealed that the participants were generally (fairly) sensitive, confident, attentive and enjoyable in intercultural interactions and respected cultural differences when communicating with people in the Chinese culture, consistent with the findings in many existing studies (Anderson et al., 2006, Chen \& Starosta, 2000; Christmas \& Barker, 2014; Liu, 2017, 2018b; Liu \& Liu, 2015; Lukesová, 2015; Martinsen, 2011; Sarwari \& Wahab, 2017; Straffon, 2003; Tabatadze \& Gorgadze, 2014). Meanwhile, the participants reported to be (highly) willing to communicate with others in Chinese, as found in Liu (2017, 2018b) and Yousef, Jamil \& Razak (2013).

Correlation analyses revealed that IENG (interaction engagement), IC (interaction confidence) and ISS (overall intercultural communication sensitivity) were significantly positively related to AECPCC (ability to effectively communicate with people from the Chinese culture), and that IENG was significantly correlated with OCC (openness to the Chinese culture), as found in Liu (2017, 2018a). Understandably, if a respondent is (more) 
engaged, confident and/or generally sensitive in intercultural interactions, he/she is highly likely to be (more) open to the Chinese culture and able(r) to effectively communicate with people from the Chinese culture, or vice versa. Unexpectedly, none of the ISS scales were significantly correlated with any measured linguistic, demographic or psychological variables, similar to the finding in Liu (2018b) and Yurtseven and Altun (2015) but unlike that in many other existing studies (Çiloğlan \& Bardakç1, 2019; Liu, 2017; Olson \& Koeger, 2001; Peng, 2005; Straffon, 2003; Yilmaz, 2019). This might be because the participants in the present study were (too) diverse in their backgrounds, and/or because the significance level was set to be too low ( $\mathrm{p} \leq .0029)$ to avoid Type I error. Nevertheless, the participants' self-rated openness to the Chinese culture was significantly positively related to their self-rated ability to effectively communicate with people from the Chinese culture, overall willingness to communicate in Chinese, and proficiency in listening, speaking and overall Chinese. This indirectly justifies the positive relationship between these measured variables and intercultural communication sensitivity, though the coefficients were not statistically significant in the present study. These findings not only need to be confirmed but also justify the need for further research.

Meanwhile, regression analyses revealed that AECPCC (ability to effectively communicate with people from the Chinese culture) was a powerful positive predictor for IENG (interaction engagement), and that AECPCC and UOC (use of Chinese) were powerful positive predictors for each of the other ISS scales except RCD (respect for cultural differences). These findings not only further confirm the close relationship between interactants' ability to effectively communicate with people from the Chinese culture and their intercultural communication sensitivity but also reveal the importance of using a SL/FL in intercultural communication sensitivity.

\section{Conclusions}

The present study investigated the predicting effects of linguistic, psychological and demographic variables on international students' intercultural communication sensitivity when immersed in the Chinese culture. Analyses of the data revealed the following findings:

1) the ISS and its subscales were (highly) reliable,

2) the participants were generally (fairly) sensitive, confident, attentive and enjoyable in intercultural interactions and respected cultural differences when communicating with people from the Chinese culture,

3 ) interaction engagement, interaction confidence, and overall intercultural communication sensitivity were significantly positively related to the participants' ability to effectively communicate with people from the Chinese culture; interaction engagement was also significantly correlated with the participants' openness to the Chinese culture, and

4) AECPCC (ability to effectively communicate with people from the Chinese culture) and UOC (use of Chinese) were powerful positive predictors for each of the ISS scales except RCD (respect for cultural differences).

These findings indicate that intercultural communication sensitivity is actually affected or mediated by such linguistic, psychological and demographic variables as proficiency in the target language, exposure and use of the target language, intercultural communication competence, openness to the target culture and willingness to communicate with others in the target language. As an interactant becomes more proficient in and has more use of the target language, gets involved in more intercultural communication, and becomes more open to the target culture and more willing to communicate with others in the target language, he/she will become more sensitive and more competent in intercultural interactions with people from the target culture (Anderson et al., 2006; Liu, 2018b; Engle \& Engle, 2004; Olson and Koeger, 2001; Yousef et al., 2013; Zhou \& Peng, 2007). He/She may then become more appreciative of the target culture and aware of cultural differences, gain a more globalized view and learn more from his/her study-abroad experiences, as reported in Liu (2018b). This is especially so in today's society as overseas education increases so fast (Bae \& Song, 2017). Since intercultural sensitivity is an important component of intercultural communication competence (Chen \& Starosta, 1996, 2000; Tamam, 2010), it is important to improve interactants' intercultural communication sensitivity (Dong et al., 2008; Liu \& Liu, 2015; Zhou \& Peng, 2007). An effective strategy is intercultural training, as proved in the current literature (Altshuler et al., 2003; Mahoney \& Schamber, 2004; Tuncel \& Paker, 2018; Zhou \& Peng, 2007). This can be done by offering orientations, seminars and/or courses on cultural differences and intercultural sensitivity and providing interactants with opportunities to practically communicate with people from the target culture. With improved intercultural sensitivity, it is easier for interactants to better adapt to a new culture, as found in Christmas and Barker (2014). They may also become less ethnocentric (Dong et al., 2008). Concurrently, it is necessary for interactants themselves to be aware of the importance of being sensitive and respecting cultural differences and not to be inclined to their comfort zones in intercultural interactions with people from the target culture (Vygostky, 1978), so that they can better adapt to a new culture and become more competent and effective in intercultural communication in the target language. Hence, both the host university and individual international students can benefit from international education.

As the world becomes more and more globalized and intercultural communication becomes increasingly common and important in almost all fields, intercultural sensitivity deserves more and continuous research. Considering that the participants were diverse in their backgrounds in the present study, future research had better recruit a more homogeneous or a larger population, which would make the findings more generalizable or more 
consistent with those in the current literature. Moreover, the participants in the present study all lived and studied in the same university in China when the research was conducted, which meant that they were fully immersed in Chinese and the Chinese culture and were probably affected and shaped by the same university culture and the university's neighboring surroundings. The profile of learners' intercultural sensitivity may be different if they (simply) engage themselves in their own cultures or are exposed to other different smaller cultures of the Chinese culture. Furthermore, analyses of qualitative data may help reveal more findings about international students' feelings, desires, sensitivity levels, and underlying causes for these when engaged in intercultural interactions in the target language, as done in Liu (2018b). Finally, more research is needed also because culture is dynamic and diverse even within the same big culture, so are intercultural communication competence and intercultural communication sensitivity (Collier, 2015).

\section{Biographical Note}

Dr. Meihua Liu is associate professor of Applied Linguistics at the Department of Foreign Languages \& Literatures, Tsinghua University, China. Her research interests mainly include EFL teaching and learning in the Chinese context, reticence and anxiety, EFL writing, and international education.

\section{References}

Alaei, M. M., \& Nosrati, F. (2018). Research into EFL teachers' intercultural communicative competence and intercultural sensitivity. Journal of Intercultural Communication Research, 47(2), 73-86. doi:10.1080/17475759.2018.1424020

Altshuler, L., Sussman, N. M., \& Kachur, E. (2003). Assessing changes in intercultural sensitivity among physician trainees using the Intercultural Development Inventory. International Journal of intercultural Relations, 27(4), 387-401. doi:10.1016/S0147-1767(03)00029-4.

Anderson, P. H., Lawton, L., Rexeisen, R. J., \& Hubbard, A. C. (2006). Short-term study abroad and intercultural sensitivity: A pilot study. International Journal of Intercultural Relations, 30(4), 457-469. doi:10.1016/j.ijintrel.2005.10.004

Bae, S.-Y., \& Song, H. (2017). Intercultural sensitivity and tourism patterns among international students in Korea: Using a latent profile analysis. Asia Pacific Journal of Tourism Research, 22(4), 436-448. doi:10.1080/10941665.2016.1276087

Bennett, M. J. (1986). A developmental approach to training for intercultural sensitivity. International Journal of Intercultural Relations, 10, 179-196. doi:10.1016/0147-1767(86)90005-2

Byram, M. (1997). Teaching and assessing intercultural communicative competence. Clevedon: Multilingual Matters.

Chen, G. M., \& Starosta, W. J. (1996). Intercultural communication competence: A synthesis. Communication Yearbook, 19, 353-383. doi:10.1080/23808985.1996.11678935

Chen, G. M., \& Starosta, W. J. (1997). A review of the concept of intercultural sensitivity. Human Communication, $1,1-16$.

Chen, G. M., \& Starosta, W. J. (2000). The development and validation of the intercultural communication sensitivity scale. Human Communication, 3, 1-15.

Christmas, C. N., \& Barker, G. G. (2014). The immigrant experience: Differences in acculturation, intercultural sensitivity, and cognitive flexibility between the first and second generation of Latino immigrants. Journal of International and Intercultural Communication, 7(3), 238-257. doi:10.1080/17513057.2014.929202

Çiloğlan, F., \& Bardakçı, M. (2019). The relationship between intercultural sensitivity and English language achievement. Journal of Language and Linguistic Studies, 15(3), 1204-1214. doi:10.17263/j1ls.631563

Cohen, J. (1988). Statistical power analysis for the behavioral sciences (2nd ed.). New Jersey: Lawrence Erlbaum Associates.

Collier, M. J. (2015). Intercultural communication competence: Continuing challenges and critical directions. International Journal of Intercultural Relations, 48, 9-11. doi:10.1016/j.ijintrel.2015.03.003

Dong, Q., Day, K. D., \& Collaço, C. M. (2008). Overcoming ethnocentrism through developing intercultural communication sensitivity and multiculturalism. Human Communication, 11(1), 27-38.

Engle, L., \& Engle, J. (2004). Assessing language acquisition and intercultural sensitivity development in relation to study abroad program design. Frontiers: The Interdisciplinary Journal of Study Abroad, 14, 219-236.

Ersoy, E., \& Uysal, R. (2018). Opinions of School Psychological Counselors on Giftedness and Gifted Students' Education. American Journal of Qualitative Research, 2(2), 120-142.

Fritz, W., Möllenberg, A., \& Chen, G.-M. (2002). Measuring intercultural sensitivity in different cultural contexts. Intercultural Communication Studies, 11(2), 165-177.

Hammer, M. R., \& Bennett, M. J. (1998). The Intercultural Development Inventory (IDI) manual. Portland, OR: 
The Intercultural Communication Institute.

Hannigan, T. P. (1990). Traits, attitudes, and skills that are related to intercultural effectiveness and their implications for cross-cultural training: A review of the literature. International Journal of Intercultural Relations, 14(1), 89-111. doi:10.1016/0147-1767(90)90049-3

Jackson. J. (2011). Host language proficiency, intercultural sensitivity, and study abroad. Frontiers: The Interdisciplinary Journal of Study Abroad, 21, 167-188.

Jimenez, A. F. (2003). Linguistic and psychological dimensions of second language attrition during and after a study abroad experience. Unpublished Ph.D dissertation, the Pennsylvania State University.

Kim, K. J. (2004). The relationship between motivation and intercultural sensitivity in English achievement. English Teaching, 59(4), 97-120.

Kotluk, N., \& Kocakaya, S. (2018). Culturally Relevant/Responsive Education: What do teachers think in Turkey. Journal of Ethnic and Cultural Studies, 5(2), 98-117.

Kratt, D. (2018). Teachers' perspectives on educator mental health competencies: A qualitative case study. American Journal of Qualitative Research, 2(1), 22-40.

Liu, M. (2017). Adult CSL learners' willingness to communicate in Chinese: The effects of cultural, affective, and linguistic variables. Psychological Reports, 120(3), 423-442. doi:10.1177/0033294117692808

Liu, M. (2018a). Bilingual/Multilingual learners' willingness-to communicate in and anxiety on speaking Chinese and their associations with self-rated proficiency in Chinese. International Journal of Bilingual Education and Bilingualism, 21(1), 54-69. doi:10.1080/13670050.2015.1127889

Liu, M. (2018b). Assessing intercultural sensitivity and effectiveness: Adult learners of Chinese as a L2. In D. M. Velliaris (Ed.), Study abroad contexts for enhanced foreign language learning (pp. 70-95). Singapore: IGI Global Publishing.

Liu, M., \& Liu, S. (2015). Changes in intercultural communication competence and self-identities while study abroad: An interview study. Foreign Language Education, 1, 65-68.

Lukesová, M. (2015). Student reflection on the development of intercultural competence through the education abroad experience. Asian Social Science, 11(21), 1-14.

Mahoney S. L., \& Schamber J. F. (2004). Exploring the application of a developmental model of intercultural sensitivity to a general education curriculum on diversity. The Journal of General Education, 53(3-4), 311-334. Retrieved from https://www.jstor.org/stable/27797998

Martinsen, R. (2011). Predicting changes in cultural sensitivity among students of Spanish during short-term study abroad. Hispania, 94(1), 121-141.

Matsumoto, D., \& Hwang, H. C. (2013). Assessing cross-cultural competence: A review of available tests. Journal of Cross-cultural Psychology, 44(6), 849-873. doi:10.1177/0022022113492891

McCroskey, J. C. (1992). Reliability and validity of the willingness to communicate scale. Communication Quarterly, 40, 16-25. doi:10.1080/01463379209369817

Morales, A. (2017). Intercultural sensitivity, gender, and nationality of third culture kids attending an international high school. Journal of International Education Research, 13(1), 35-44.

Nieto, C., \& Booth, M. Z. (2009). Cultural competence: Its influence on the teaching and learning of international students. Journal of Studies in International Education, 14(4), 406-425. doi:10.1177/1028315309337929

Olson, C. L., \& Kroeger, K. R. (2001). Global competency and intercultural sensitivity. Journal of studies in International Education, 5, 116-137. doi:10.1177/102831530152003

Penbek, S., Şahin, D. Y., \& Cerit, A. G. (2012). Intercultural communication competence: A study about the intercultural sensitivity of university students based on their education and international experiences. International Journal of Logistics Systems and Management, 11(2). doi:10.1504/IJLSM.2012.045425

Peng, S. (2005). Intercultural communication research in China: Status quo, problems, and suggestions. Journal of Hunan University (Social Science), 4, 86-91.

Pritchard, R. M. O, \& Skinner, B. (2002). Cross-cultural partnerships between home and international students. Journal of Studies in International Education, 6(4), 323-353. doi:10.1177/102831502237639

Rahimi, A., \& Soltani, A. (2011). Teachability of intercultural sensitivity from the perspective of ethnocentrism vs. ethnorelativism: An Iranian experience. Iranian Journal of Applied Linguistics, 14(1), 109-134.

Sarwari, A. Q., \& Wahab, M. N. A. (2017). Study of the relationship between intercultural sensitivity and intercultural communication competence among international postgraduate students: A case study at University Malaysia Pahang. Cogent Social Sciences, 3, 1310479. doi:10.1080/23311886.2017.1310479

Shively, R. L. (2008). Politeness and social interaction in study abroad: Service encounters in L2 Spanish (Unpublished Ph.D dissertation). University of Minnesota.

Straffon, D. A. (2003). Assessing the intercultural sensitivity of high school students attending an international school. International Journal of Intercultural Relations, 27(4), 487-501. doi:10.1016/S01471767(03)00035-X

Tabatadze, S., Gorgadze, N. (2014). Intercultural sensitivity of primary school teachers of Georgia. International Journal of Education and Research, 2(6), 281-300.

Tamam, E. (2010). Examining Chen and Starosta's model of intercultural sensitivity in a multiracial collectivistic 


$$
\text { country. Journal of Intercultural Communication Research, 39, 173-183. }
$$
doi:10.1080/17475759.2010.534860

Tamam, E., \& Krauss, S. E. (2014). Ethnic-related diversity engagement differences in intercultural sensitivity among Malaysian undergraduate students. International Journal of Adolescence and Youth, 22(2), 137150. doi:10.1080/02673843.2014.881295

Tuncel, I., \& Paker, T. (2018). Effects of an intercultural communication course in developing intercultural sensitivity. International Journal of Higher Education, 7(6), 198-3211. Retrieved from http://ijhe.sciedupress.com

Vygostky, L. S. (1978). Mind in society: The development of higher psychological processes. Cambridge, MA: Harvard University Press.

Yilmaz, D. (2019). The investigation of public and private university students' intercultural sensitivity. European Journal of English Language Teaching, 5(1), 78-93. doi:10.5281/zenodo.3374918

Yousef, R., Jamil, H., \& Razak, R. (2013). Willingness to communicate in English: A study of Malaysian preservice English teachers. English Language Teaching, 6(9), 205-216. doi:10.5539/elt.v6n9p205

Yu, T., \& Chen, G. M. (2008). Intercultural sensitivity and conflict management styles in cross-cultural organizational situations. Intercultural Communication Studies, 17(2), 149-161. Retrieved from https://web.uri.edu/iaics/files/12-Tong-Yu-GM-Chen.pdf

Yurtseven, N., \& Altun, S. (2015). Intercultural sensitivity in today's global classes: Pre-service teachers' perceptions. Journal of Ethnic and Cultural Studies, 2(1), 49-54.

Zhou, X., \& Peng, X. (2007). Exploring the effect of culture learning on intercultural sensitivity. Journal of Sichuan College of Education, 7, 88-94. 